\title{
Impact of globalization and digitalization on the efficiency of environmental development of territories
}

\author{
$B$ Meskhi $^{1}, V$ Bondarenko $^{2}, I$ Efremenko ${ }^{1,2}, T$ Romanishina $^{2}, D$ Rudoy ${ }^{1, *}$, and $A$ \\ Olshevskaya $^{1}$ \\ ${ }^{1}$ Don State Technical University, Gagarin sq., 1, Rostov-on-Don, 344003, Russia \\ ${ }^{2}$ Rostov State University of Economics, B. Sadovaya, st., 69, Rostov-on-Don, 344002, Russia
}

\begin{abstract}
Territory marketing is a popular area in terms of developing directions for territorial development and practical steps for the implementation of this activity. The interest in this area has been updated due to the development of globalization and increased competition of territories with each other. However, in the scientific literature there are many similar concepts related to territorial marketing, territorial marketing and regional marketing, which requires understanding and understanding of their essential characteristics and relationships. Along with this, it is of objective interest to characterize the main approaches to territory marketing due to their high demand for Russian reality.
\end{abstract}

\section{Introduction}

Interest in territorial marketing, marketing of territories, regional marketing and other names that characterize both the general management concept of the development of territories, as well as the tools and practical solutions used in the period of a developed market, are dictated by objective necessity. As part of the search tasks of this study, we need to determine the terminological content of this area, its relevance, the characteristics of the solutions used in planning the development of territories and the marketing tools used.

At the present stage of developed market relations, characterized, at the same time, by globalization and glocalization in the economy, marketing concepts and solutions in territorial development are becoming justified, coupled both by the customer focus of the goods and services offered to target audiences, and by competition for attracting investment, human and other resources for the implementation of large-scale projects.

This orientation is determined in view of the understanding and objective manifestation of the new role of regions (territories) in world development, within which, within the framework of glocalization, there is a tendency for cooperation between neighboring territorial units and building joint programs for successful functioning in certain market segments. As part of the developing globalization, the regions become independent or partially independent players in domestic and foreign markets, competing with each other

${ }^{*}$ Corresponding author: dmitriyrudoi@gmail.com 
and building an independent strategy of promotion and development for a prolonged period. Describing these trends, for example, A. Kaganovich, as well as a number of foreign authors emphasize, along with the countries of the world, certain regions have become fullfledged participants in the trade system, investment processes and economic development [15], which made the marketing tools and elements of " soft power ", which form the marketing support of the image and brand management of territories, which actualizes the interest in marketing territories.

\section{Materials and methods}

Within the framework of the study, the marketing of the territory and its derivatives, such concepts of territorial marketing and regional marketing are also subject to analysis, key characteristics and main approaches put forward by specialists in this area are identified. The methods of description, analytical consideration, comparison, as well as analysis and synthesis of the results obtained are used.

\section{Discussion}

Describing the point of view on understanding the role of marketing in territorial development, we note that, for example, A. Ovsyannikova, I. Sokolova consider regional marketing as a new style of thinking for managers, which helps to attract funds for the development of the territory along the lines and lines identified within the strategic plan.

Further, characterizing the construction of domestic specialists, we point out that, for example, Y. Dubova emphasizes the need to update the approach to regional development, which includes consumer orientation, market transformation taking into account consumer demands, the formation and promotion of the "name" of your region, as refers to regional marketing [13]. This author proposes to consider the specifics of regional marketing by means of the marketing mix (marketing complex) formed for a certain territory and, in fact, equates territory marketing and regional marketing, also saying that the territory marketing system coincides with the generally accepted interpretation of the marketing concept 13].

Other authors - Umavov Yu., Gazaliyeva P. also operate with the concept of regional marketing, defining it as "a modern philosophy of territory management based on the principles of marketing and management". They also highlight the need for regional marketing to target audiences and their needs. Their interpretation of regional marketing in sense and meaning coincides with the marketing of a territory, where a territory is understood as a certain region.

Gaynanov D., Migranova L., Sayfullina L. talk about a specific form of marketing, calling it territorial marketing, and believe that it consists in identifying and forming the competitive advantages of a certain territory in the perception of its target audiences, as well as meeting their needs [10].

When considering the above interpretations, we note that there are no significant differences between regional marketing and territory marketing or territorial marketing. Since, in fact, we are talking about a marketing orientation in the functioning of the socioeconomic system of the region and its management on market principles. However, in the specialized literature, various interpretations of these concepts are introduced and a differentiation is made between them, coupled, first of all, with the direction of marketing efforts within the region or outside it.

For example, A. Biglova, E. Gastenova clarify that "regional marketing is marketing carried out at the regional level, reflecting its specifics and features and the marketing of a territory is aimed at improving its image and attracting external players" [2]. 
According to the ideological constructions of A. Pankrukhin, territorial marketing is a more complete and complex concept, which includes marketing of territories and marketing in the territory (regional marketing) as components (Figure 1).

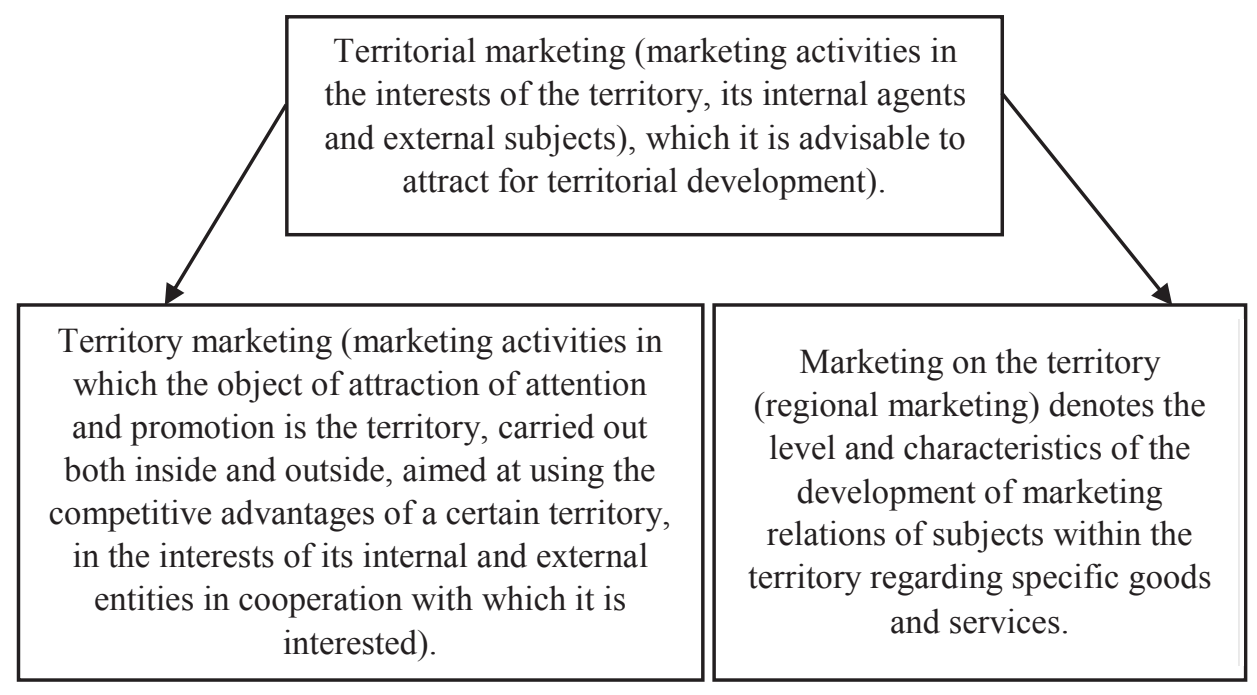

Fig. 1. Interpreting Territorial Marketing.

As you can see from the interpretations presented in Figure 1, this division is conditional, since territorial marketing and marketing of the territory in the sense of disclosure seem to be almost identical. Nevertheless, the point of view of a broader understanding of territorial marketing can also be justified in the N., Midler E. emphasize the need to perceive the marketing of territories in a complex, as a tool for managing the territory for long-term development, based on forecasts and assessment of the situation, as well as an independent type of marketing activity in relation to territorial development.

\section{Result}

Within the framework of the marketing of the territory, it is conditionally possible to single out several areas that have certain specifics, although all of them, one way or another, rely on the development of a strategy for the development of the territory, associated with attracting investments, assessing the possibilities and prospects of the territory, its positioning and promotion, as well as image management and brand formation (Figure 2). 


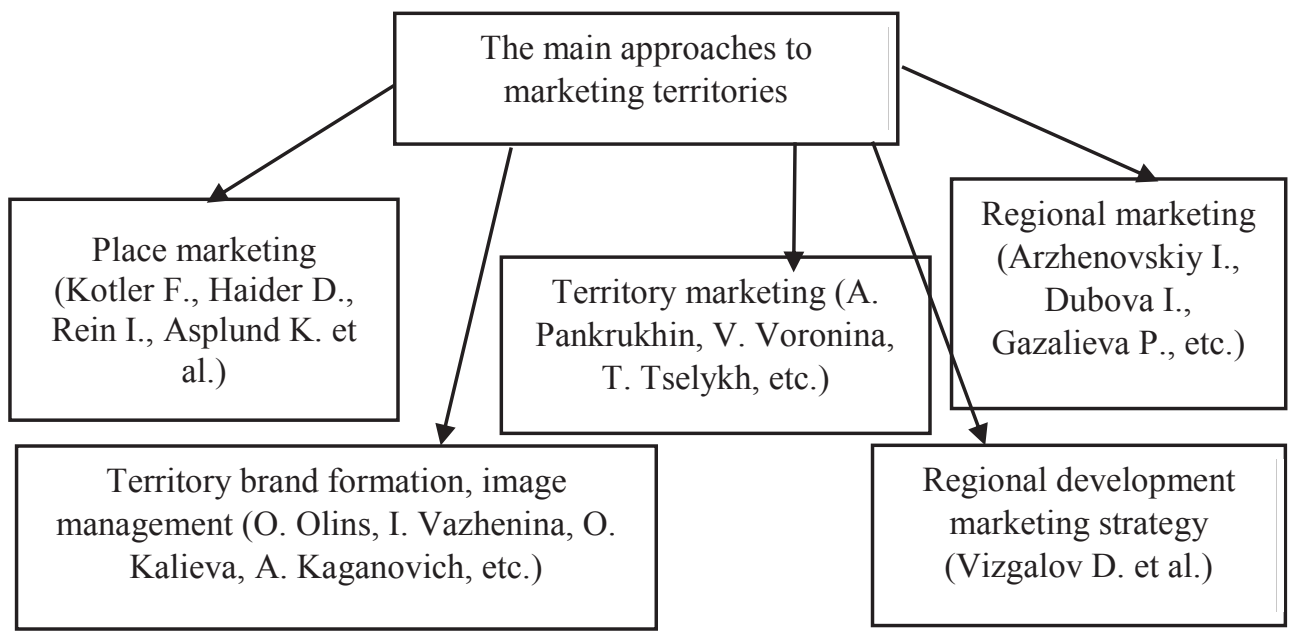

Fig. 2. The main approaches to marketing territories.

Despite the emphasis of the noted approaches, we emphasize once again that all researchers, for the most part, adhere to similar positions, but pay deeper attention to certain components within the framework of the areas we have identified.

We also note that in Russian conditions, state marketing is also relevant and analyzed by various researchers in relation to the implementation of territorial development, which is interpreted by a number of specialists as aggregated management measures within the framework of the public administration system in relation to the country or its individual regions [12]. This presupposes a marketing orientation of the public administration system [14] and, accordingly, largely coincides with the point of view on territory marketing as a market concept for territorial development management.

In addition, it should be noted that the key value in all theoretical constructions belongs to competitive positioning, which, for example, A. Pankrukhin defines as "a strategic decision based on the results of SWOT analysis, research of target markets". Sachuk T. similarly defines the positioning of the territory, also focusing on differentiation from competing regions and dividing the supply of the territory within the framework of preferences for different groups of the population.

Arzhenovskiy I. emphasizes that positioning is "... strengthening the strengths of the region, which, relying on what has been achieved, are directed to the future" [1].

Foreign researchers, for example, F. Kotler, D. Haider, I. Rein, K. Asplund, believe that, as a priority, territories should determine for themselves what resources they have in comparison with competing regions and position their territory, thus, to differentiate from in the minds of target audiences from other territories [17].

These researchers, describing the marketing strategy of a place, highlight positioning and creating an attractive image as the first element, then emphasize the importance of incentives to attract external and internal consumers; focus on the delivery of products and services of the territory in the most convenient form for consumers and emphasize the importance of informing target audiences about the useful distinctive features of the positioned place.

They conclude that a certain territory (place) needs to focus on the correct choice of target audiences, namely: to choose the attraction of those persons and business structures with whom it is worth communicating and which should be targeted to attract. It is also necessary to decide on those who do not require special attention, but can cooperate with representatives of a given place for its development, and it is also necessary to "cut off" the 
audience that is not desirable for a particular place, which implies the elimination of incentives that may attract it.

Describing the desired target groups, for example, Zenker S., Brown E. single out the newcomers living in the area, as well as the areas of business and management (Figure 3).

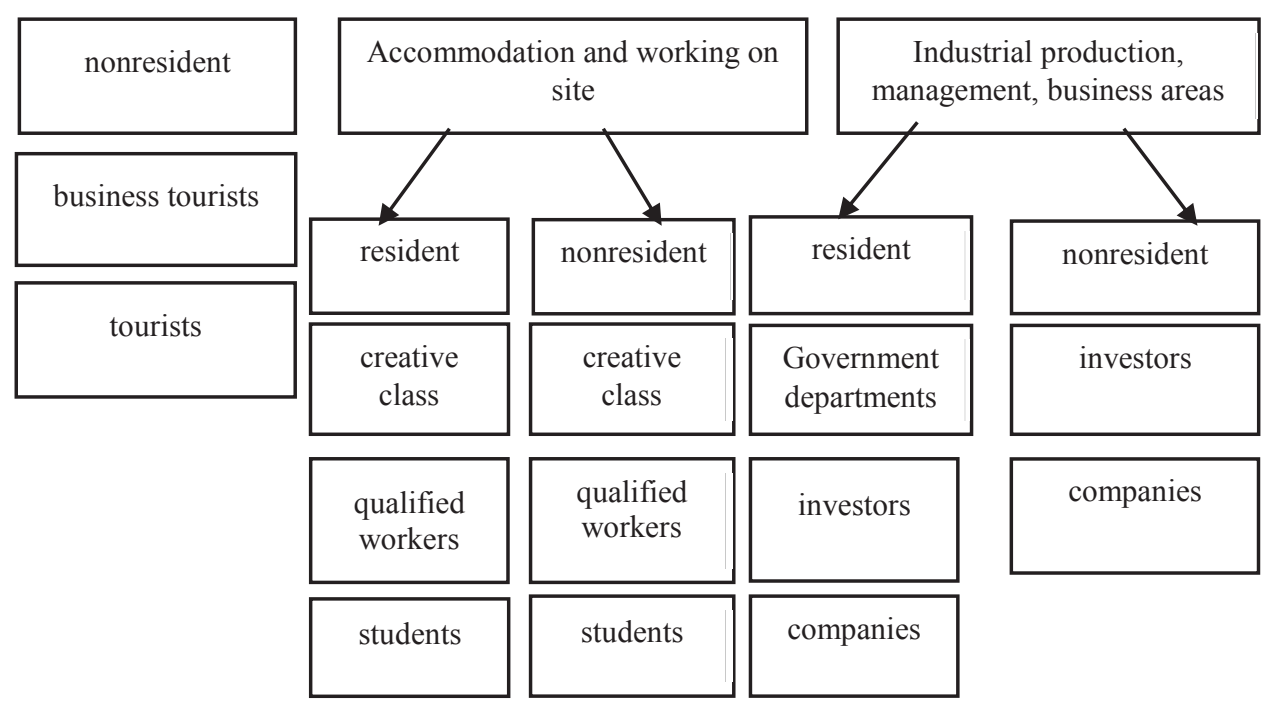

Fig. 3. Target audiences of territory marketing (according to Zenker S., Brown E.).

As you can see, with this approach, target audiences include internal and external consumers (individuals), governing bodies, internal and external business, and investors. A number of foreign researchers, however, emphasize that successful work with target audiences within the framework of territory marketing is possible if local residents are involved, in fact, as early adopters in this process, who further contribute to positioning the territory. If local residents are involved in this process, then this is an essential factor leading to success.

So, for example, G. Wooley calls them the "key" to ensure the viability (essentially competitiveness) of the territory. This author mainly talks about cities, urban agglomerations, but since in Russia it is urban agglomerations that act as centers of territorial development, this point of view is fair and can be transferred to larger territories. Another researcher R. Mackintosh speaks about the need for joint work of the population and public authorities in the strategic planning of development in the marketing of the territory. He also believes that the correct motivation of the population and understanding of the goals set for the territory contribute to the effectiveness of the decisions taken by the authorities.

Based on the needs of target audiences, F. Kotler et al. Pay great attention to positioning, but much less attention to promoting places, since they believe that a successful (safe) place, having an identity, a demanded environment, being a service provider and a zone of attraction for target audiences, can be successful in competing with other places [17].

In this context, the domestic researcher A. Demyanenko adheres to a similar point of view with them, who believes that the promotion of the product and service offer of a not very successful territory to foreign markets will help to consolidate its failure, since it will allow consumers to accelerate the detection of unsatisfactory characteristics for themselves [11]. 
Pankrukhin P. in relation to territorial marketing examines the competitiveness of the territory (which is directly dependent on the territorial product, its pricing, location and promotion, that is, the main elements of the marketing mix) and its positioning.

This author believes that the positioning of a territorial product (various resources of a territory) can be successful if it is initially aimed at satisfying the needs of consumers of a territory (external and internal). They highlight the main strategies of the territory based on the positioning of its advantages: image marketing (forms a favorable image based on the real qualities of the territory); attractiveness marketing (achieved by creating attractive conditions or offering any preferences); infrastructure marketing (consists in building up the necessary infrastructure, both for business, production, and for the population - social, cultural); marketing of the population (is of a twofold nature: on the one hand, it can be attracting human capital to life and work in a certain territory; on the other hand, it is attracting business to the territory due to the availability of the necessary human resources).

An equally interesting direction, largely explaining the implementation of the stages of strategic planning and development of territories, is the marketing strategy of the regions of Vizgalov D., which focuses on such elements as positioning and promotion of the region [7, 8]. Within the framework of positioning, it is determined which message will be broadcast to target audiences, and when promoting the region, this information is communicated to them in the most effective way.

Most researchers, characterizing the intangible assets of a territory from the point of view of the prospects for its promotion, place a certain emphasis on the reputation, image and brand of the region. Thus, I. Vazhenina defines the reputation of a territory as "the value beliefs that have developed among representatives of target groups based on open information and personal experience regarding a certain territorial entity" [6].

Other researchers - Bolshakov S., Grigoriev A. emphasize the importance of reputation capital for regional development and its close connection with the image of the territory [3].

We also note that within the framework of the concepts accepted in the scientific community, the image of a territory is usually understood as "a set of sensations that people have about the climatic, historical, ethnographic, socio-economic, political and moralpsychological, as well as other features of a certain territory" [4].

Accordingly, under the brand of the territory, this author understands "a set of values formed in the minds of consumers, reflecting the originality, unique original consumer properties of the territory, which are in stable demand among its consumers" [4].

Similar point of view is held by O. Kaliyeva, who, in her interpretation, speaks of the complex concept of the brand-image of the territory, defining it as follows: "this is an established stable image that causes certain associations in the minds of the population and consumers of the territory".

Agreeing, on the whole, with the importance of image and brand in promoting the territory within the framework of territorial marketing, let us explain that, in our opinion, the issues of involving intangible assets in this process seem significant.

At the same time, no less significant, and in many respects of key importance, are the real circumstances and the material, tangible potential existing in the region, on the basis of which an image and a strong brand should and can be formed. In the absence of real characteristics that are significant for the consumers of the territory, according to the ideas set forth earlier by F. Kotler and co-authors, with the active promotion of the territory, this will accelerate its unsuccessful position in comparison with competing regions.

\section{Conclusion}

For this reason, we can conclude that marketing of territories requires a sound balance based on real benefits that are significant for consumers of the territory (external and 
internal) incentives and motivators for cooperation with it, which are fixed in intangible image support and a brand that affect target audiences and promote increasing the potential of the territory. In this vein, when developing a marketing strategy for the development of a territory, the key areas are attracting investments to activate the selected priority areas and development based on the existing advantages of a strong territorial brand positioned and promoted in the communication space to its target audiences.

\section{References}

1. S. Zenker, E. Braun, 39th European Marketing Academy Conference (Copenhagen, Denmark, 2010)

2. A. Altybayev, A. Zhanbyrbayev, B. Meskhi, D. Rudoy, A. Olshevskaya, A. Prohorova, E3S Web of Conferences 135, 01078 (2019) https://doi.org/10.1051/e3sconf/201913501078

3. Y. Lachuga, A. Soloviev, A. Matrosov, I. Panfilov, V. Pakhomov, D. Rudoy, IOP Conf. Series: Earth and Environmental Science 403, 012055 (2019) doi:10.1088/1755$1315 / 403 / 1 / 012055$

4. A. Zavaliy, S. Volozhaninov, O. Shiian, D. Rudoy, A. Olshevskaya, E3S Web of Conferences 175, 05003 (2020) https://doi.org/10.1051/e3sconf/202017505003

5. I. Boukhanef, A. Khadzhidi, L. Kravchenko, Z. Ayoub, K. Abdennour, E3S Web of Conferences 175, 12002 (2020) https://doi.org/10.1051/e3sconf/202017512002

6. V. Kravchenko, L. Kravchenko, V. Oberemok, E3S Web of Conferences 175, 05017 (2020) https://doi.org/10.1051/e3sconf/202017505017

7. Y. Chayka, V. Zhurba, N. Krivtsova, A. Khadzhidi, P. Voshchevoz, N. Ugrekhelidze, E3S Web of Conferences 175, $09007 \quad$ (2020) https://doi.org/10.1051/e3sconf/202017509007

8. L. Chernykh, A. Theodossiou, Multinational Finance Journal 15(3-4), 193-216 (2011)

9. J. Noss, P. Toffano, Journal of Banking \& Finance 62, 15-27 (2019) doi: 10.1016/j.jbankfin.2015.09.020

10. E. Kahveçi, B. Wolfs, Banks and Bank Systems 13(3), 48-57 (2018)

11. L. Spierdijk, S. Shaffer, T. Considine, Journal of Banking and Finance (2017) doi: 10.1016/j.jbankbn.2017.07.012

12. O. Pak, Eurasian Economic Union The Quarterly Review of Economics and Finance (2018) https://doi.org/10.1016/j.qref.2018.07.008

13. N. Vanteeva, C. Hickson, Gerschenkron revisited: The new corporate Russia Journal of Economic 49(4), 978-1007 (2015)

14. Digital Single Market. POLICY. Europe 2020 strategy (European Comission, 2018) ec.europa.eu

15. Smarter, greener, more inclusive? INDICATORS TO SUPPORT THE EUROPE 2020 STRATEGY. 2016 edition Lux: Publications Office of the European Union (Eurostat, 2016) 